\title{
SIMULASI GERAK GAJAH DENGAN MENGGUNAKAN METODE POSE TO POSE
}

\author{
T. Rafli A ${ }^{1)}$ \\ 1) Dosen Program Studi Informatika, Fakultas Ilmu Komputer, Universitas Almuslim Bireuen \\ e-mail: rafliabdillah2014@gmail.com
}

\begin{abstract}
Making an animated film involves a fairly long procedure in order to produce good quality. Having a regular and on schedule production flow is absolutely necessary. In the process of producing motion in animation, either $2 D$ or $3 D$, it requires the right technique to match the plan. Pose to pose is one of the 12 principles of animation used by animators to produce smoother and more efficient movements when compared to movements using the straight ahead technique. The results obtained are pose to pose on the elephant's movement which can later be used as a reference for animators to make animations with $3 D$ blender animation software.
\end{abstract}

Keywords:

\begin{abstract}
Abstrak
Membuat sebuah film animasi melibatkan prosedur yang cukup panjang agar menghasilkan kualitas yang baik. Memiliki alur produksi yang teratur dan sesuai jadwal tentu sangat mutlak dibutuhkan. Dalam proses produksi gerakan dalam animasi baik $2 \mathrm{D}$ atau 3D membutuhkan teknik yang tepat agar dapat sesuai dengan perencanaan. Pose to pose merupakan salah satu dari 12 prinsip animasi yang digunakan animator agar menghasilkan gerakan yang halus dan lebih efisien dalam pengerjaannya jika dibandingkan gerakan menggunakan teknik straight ahead. Hasil yang didapatkan yaitu pose to pose pada gerakan gajah yang nantinya dapat dijadikan referensi animator membuat animasi dengan software animasi blender 3D.
\end{abstract}

Kata Kunci: Pose to pose; 12 Prinsip Animasi; Inbetween; Ekstreme Pose; 3D.

\section{Pendahuluan}

Perjalanan sejarah animasi dimulai pada tahun 1883 ketika muncul istilah stroboskopik sebagai dasar sinematografi yang membuat benda bergerak secara memutar. Kemudian, seseorang bernama H.W. Goodwin menemukan film dari seluloid yang dapat menampung gambar sekaligus.

Karena penemuan Goodwin ini, Thomas Edison selanjutnya mengembangkan penemuan tersebut dengan menghasilkan gambar bergerak di dinding dengan bantuan serangkaian roda.

Pada tahun 1899, suara direkam untuk pertama kalinya dengan menggunakan alat perekam magnetik, Squad. Tetapi, Walt Disney lah yang membuat film animasi bersuara untuk pertama kalinya. Film tersebut adalah Mickey Mouse yang diputar perdana pada tahun 1928.

Selain itu pada tahun 1937, Disney juga memproduksi film Snow White and the Seven Dwarfs yang berhasil menjadi film animasi terpanjang berwarna pertama. Karena banyaknya pencapaian yang diraih Disney, maka tahun 1928-1950an disebut sebagai "The Golden Age of Cartoon" yang identik dengan Walt Disney.

Selain film animasi dari Amerika Serikat seperti Disney, Jepang juga memproduksi film animasi mereka yang dikenal sebagai anime, Squad.

Anime ini berhasil mendominasi layar televisi pada era 1950-1980an, salah satunya yaitu Doraemon.

Selanjutnya memasuki tahun 1980-an, perkembangan teknologi digital memegang andil yang cukup besar dalam sejarah animasi. Pada era tersebut, banyak perubahan yang terjadi seperti Toy Story yang berhasil 
menjadi film animasi berbentuk 3D pertama dengan durasi 1 jam 21 menit. Perkembangan teknologi tersebut juga kemudian banyak memunculkan film animasi lain seperti Inside Out, Despicable Me, Moana, Zootopia, Coco, dan masih banyak lagi.

Untuk membuat animasi yang bagus dan menarik Studio Disney biasanya menggunakan 12 prinsip animasi. Salah satu prinsip yang digunakan adalah metode Pose to pose. Dalam pembuatan animasi menggunakan metode pose to pose berbeda dengan straight ahead. Jika menggunakan straight ahead animator menggambar gerakan animasi satu per satu. Sementara dalam pose to pose animator menentukan beberapa pose perubahan gerak yang paling menonjol terlebih dahulu yang juga dikenal dengan extreme pose, kemudian gerakan dihaluskan dengan menambahkan gerakan antara atau inbetween.

Metode pose to pose tidak hanya digunakan pada gerakan manusia saja namun dapat juga digunakan untuk menganimasikan gerakan mahluk hidup lainnya bahkan pada benda mati sekalipun.

Berdasarkan latar belakang tersebut penulis tertarik untuk meneliti simulasi gerak gajah dengan menggunakan metode pose to pose.

\section{Metode}

Metode yang digunakan dalam penelitian ini adalah dengan metode studi pustaka, yaitu metode pencarian dan pengumpulan data dengan cara mencari referensi, literature atau bahan - bahan teori yang diperlukan dari berbagai sumber wacana yang berkaitan dengan penelitian yang dilakukan. Pengujian metode perbandingan dilakukan dengan melalui beberapa tahapan, diantaranya adalah:

\section{A. Analisa Kebutuhan}

Analisa merupakan suatu kegiatan yang dilakukan untuk mengetahui lebih detail bagaimana sistem yang akan dikembangkan dan diterapkan sehingga memperoleh hasil yang maksimal. Adapun langkah - langkah yang dilakukan penulis dalam mengidentifikasi dan menganalisi masalah kebutuhan - kebutuhan yang diperlukan seperti kebutuhan software dan hardware. Bahan - bahan yang dibutuhkan dan metode yang dilakukan dalam pengumpulan data, kemudian mendeskripsikan langkah tersebut kedalam tahapan perancangan sistem dan mengimplementasikannya kedalam sebuah aplikasi yang akan dibuat.

B. Perancangan simulasi animasi pose to pose pada gajah

Pada bagian ini dilakukan perancangan yang mencakup perancangan diagram aktivitas, flowchart serta struktur menu daripada antarmuka media pembelajaran. Adapun peracangan secara rinci adalah sebagai berikut:

Flowchart merupakan bagan yang menunjukkan alur kerja atau apa yang sedang dikerjakan di dalam sistem secara keseluruhan dan menjelaskan urutan prosedur-prosedur yang ada di dalam sistem. Adapun flowchart pembuatan metode pose to pose ini yaitu sebagai berikut:

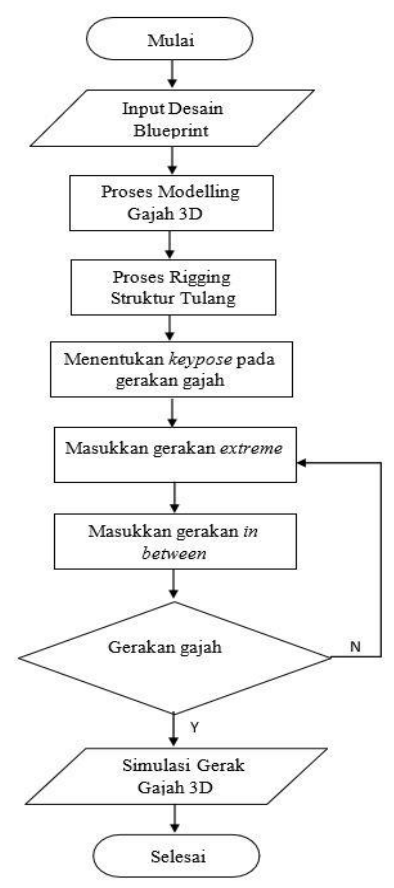




\section{Hasil dan Pembahasan}

\section{Gambar 1. Flowchart}

Pada tahap ini penulis akan melakukan pengujian terhadap metode pose to pose yang telah peneliti kerjakan sebelumnya. Pengujian bertujuan untuk mengetahui hasil metode pose to pose yang telah dibuat, apakah gerakan pada karakter gajah dapat menghasilkan gerakan yang natural dengan membandingkan keypose yang didapat dari video referensi.

A. Pose to Pose Gajah Berjalan
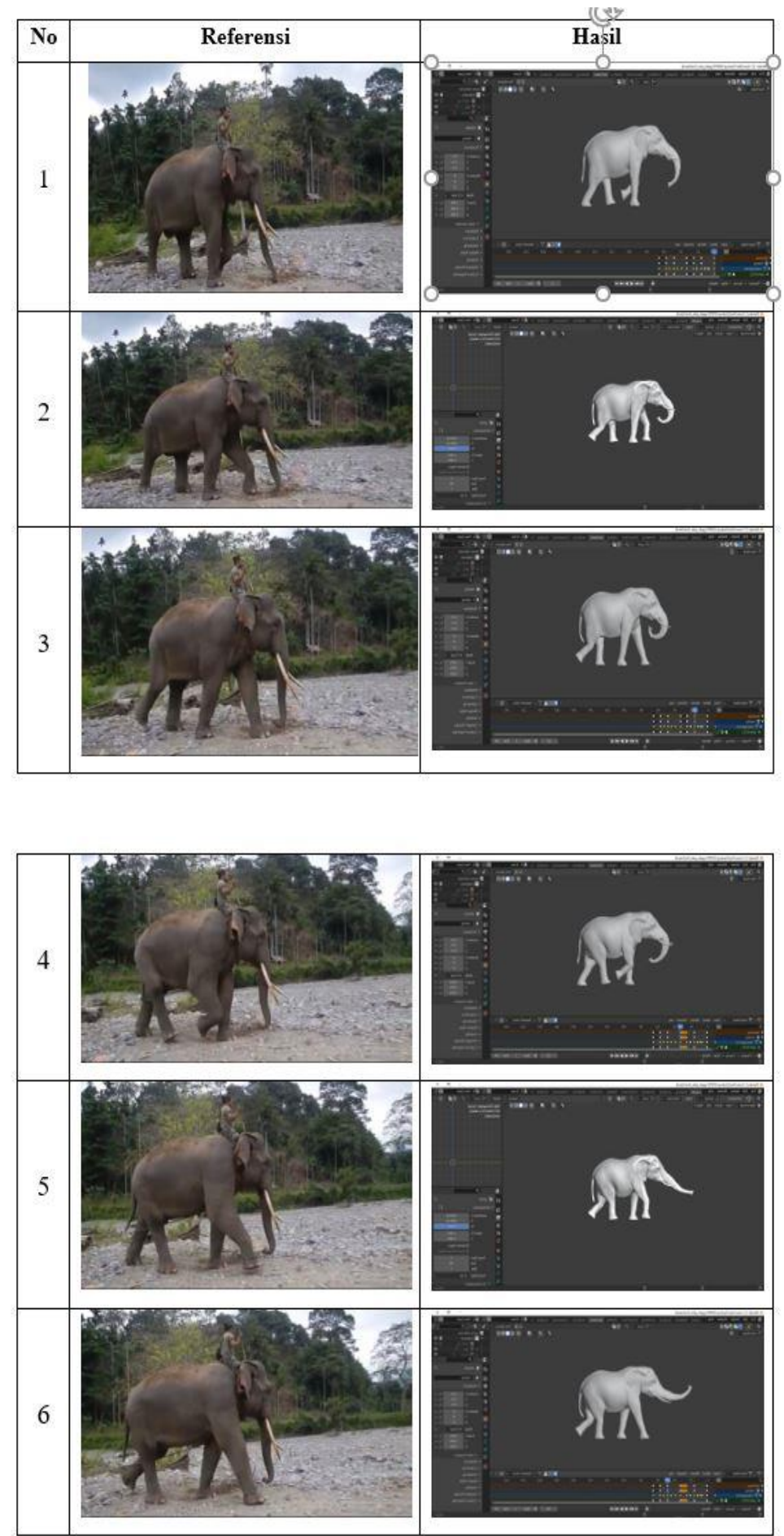

Tabel 3.1. Perbandingan gerakan gajah jalan. 
B. Pose to pose gajah duduk
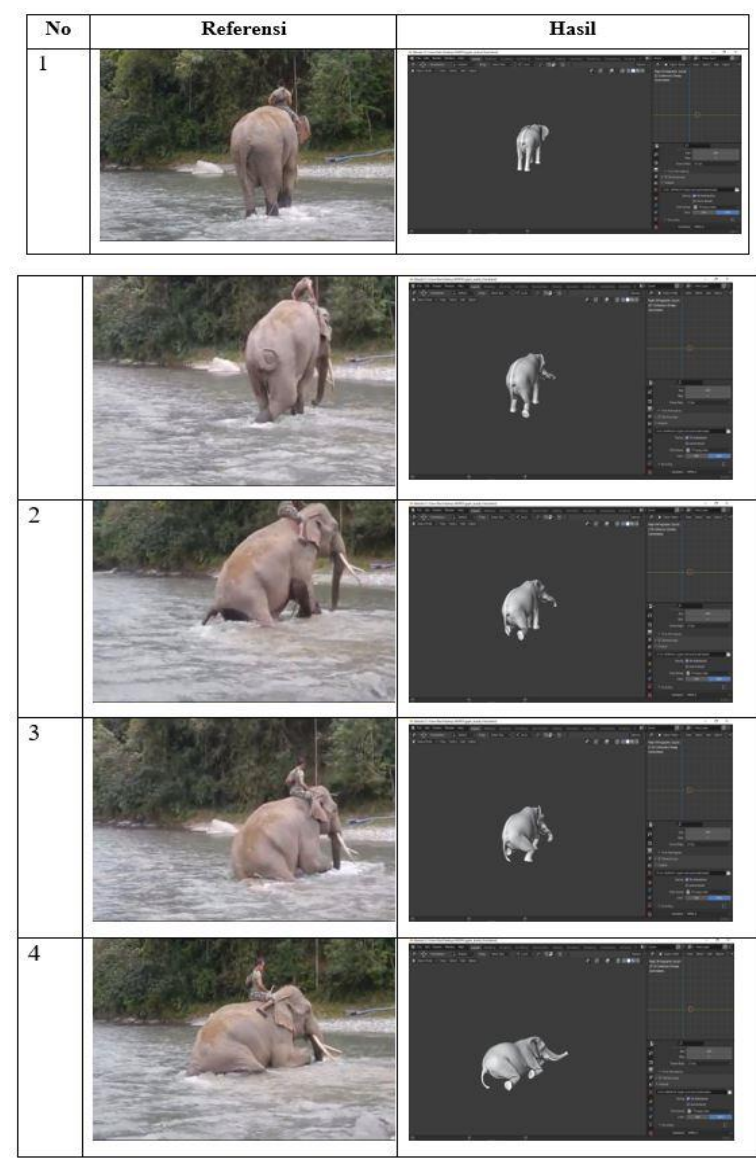

Tabel 3.2. Perbandingan gerakan gajah duduk.

C. Pose to pose gajah berdiri

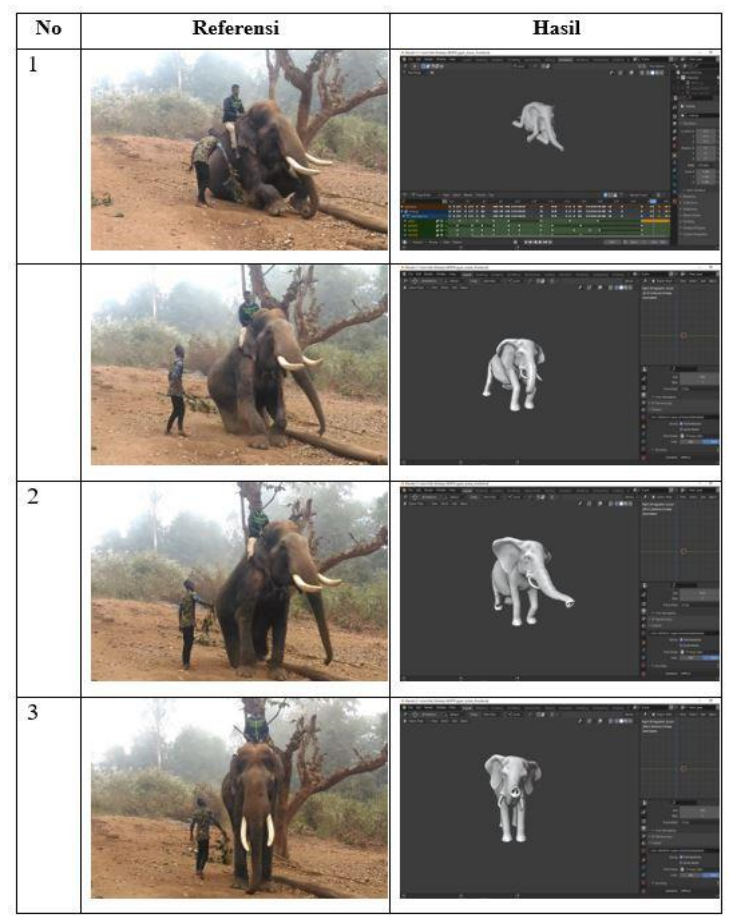

Tabel 3.3. Perbandingan gerakan gajah berdiri. 
Setelah diuji lalu dibandingkan gerakan gajah berjalan, duduk dan berdiri sesuai dengan dengan referensi dari video asli. Dengan menggunakan metode pose to pose mempermudah dan mempersingkat dalam menganimasikan objek tanpa mengurangi kemiripan Gerakan.

\begin{tabular}{|c|l|c|c|c|}
\hline No & \multicolumn{1}{|c|}{ Aksi } & Yang Diharapkan & Pengamatan & hasil \\
\hline 1 & Gajah Berjalan & Gerakan sesuai keypose & Gerakan seperti keypose & Sesuai \\
\hline 2 & Gajah Duduk & Gerakan sesuai keypose & Gerakan seperti keypose & Sesuai \\
\hline 3 & Gajah berdiri & Gerakan sesuai keypose & Gerakan seperti keypose & Sesuai \\
\hline 4 & Gajah Lari & Gerakan sesuai keypose & Gerakan seperti keypose & Sesuai \\
\hline
\end{tabular}

Tabel 3.4. Perbandingan gerakan gajah

\section{Kesimpulan}

Berdasarkan penelitian yang telah dilakukan dapat ditarik kesimpulan bahwa implementasi metode pose to pose pada simulasi gerak gajah dalam pembuatan animasi 3D memiliki persentase tingkat kemiripan dengan gerak asli objek yang terdapat pada video referensi. Hal ini ditunjukkan dengan hasil perbandingan yang telah dilakukan pada pola gerakan gajah yang terdapat pada video real dengan pembuatan animasi menggunakan pose to pose. Oleh karena itu pembuatan objek animasi 3D dengan menggunakan metode pose to pose dapat mempengaruhi tingkat kemiripan dengan objek aslinya.

\section{Daftar Pustaka}

Angga Firmansyah, M. P. (2013). Pembuatan Film Animasi 2D Menggunakan Metode Frame by Frame Berjudul "Kancil dan Siput", Jurnal Informatika Vol 14 No.4 Yogyakarta. STMIK AMIKOM.

Aski Satriawan, M. E. (2016). Analisis dan Pembuatan Rigging Karakter 3D pada Animasi 3D "Jangan Bohong Dong". Jurnal Teknik Informatika Volume 9. Batam. Politeknik Negeri Batam.

Beane Andy (2012). 3D Animation Essentials. dan Penerbit Wiley John dan Sons,Inc., Indianapolis.

Chronister James (2017). Blender Basics Classroom Tutorial Book. 5th Edition. Blender.org

Faizal, M. A. (2011). Software Blender untuk Modeling 3 Dimensi.

Nainggolan, H. (2017). Perancangan Animasi Wayang Pandawa Lima dalam Lakon Pilkada dengan Menggunakan Pose to Pose. Jurnal Teknik Informatika Volume 12. Medan. STMIK Budi Darma.

Nata Privat Available: https://bimbelprivatbandung.com/suka-nonton-marvel-yuk-kenali-dulu-sejarah-filmanimasi/

Priyatmono, Dody. (2013, Aug 29) Proses Pemuatan Karya Animasi online. Available: http : //www.dodyanimation.com/2013/08/29/proses-pemuatan-karya-animasi/.

Ramadhana Afida Rachman. (Apr 30, 2019) Suka Nonton Marvel Yuk Kenali Dulu Sejarah Film Animasi. Available: https://www.ruangguru.com/blog/yuk-mengenal-sejarah-animasi

Roberts Steve Roberts (2011). Character Animation Fundamentals Developing Skills for 2D and 3D Character Animation. dan Penerbit Elsevier Ltd. Singapore.

Salmon, S. F. (2017). Penggunaan Metode Pose to Pose dalam Pembuatan Animasi 3D Tarian Minahasa Maengket. Jurnal Teknik Informatika Volume 12. Manado. Universitas Sam Ratulangi Manado.

Victor Waeo, A. S. (2016). Implementasi Gerakan Manusia Pada Animasi 3D dengan Menggunakan Menggunakan Metode Pose to pose. Jurnal Teknik Informatika Volume 9. Manado. Universitas Sam Ratulangi Manado. 